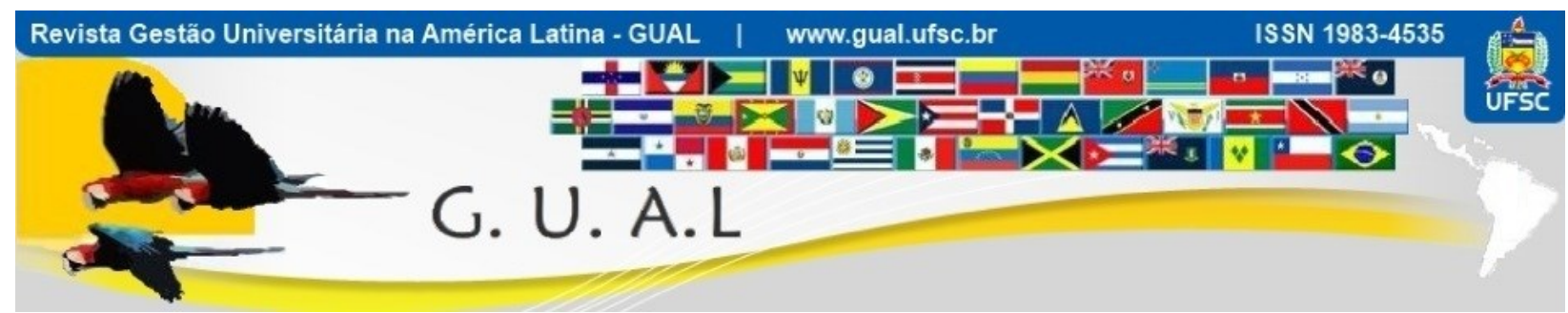

DOI: http://dx.doi.org/10.5007/1983-4535.2015v8n1p236

\title{
PRÁTICAS DE SUSTENTABILIDADE EM INSTITUIÇÕES DE ENSINO SUPERIOR: EVIDÊNCIAS DE MUDANÇAS NA GESTÃO ORGANIZACIONAL
}

\section{SUSTAINABILITY PRACTICES IN HIGHER EDUCATION INSTITUTIONS: EVIDENCE OF CHANGES IN ORGANIZATIONAL MANAGEMENT}

Socorro de Fátima da Silva Viegas, Mestre Universidade Federal Rural da Amazônia - UFRA socorroviegas83@gmail.com

Eugênia Rosa Cabral, Doutora Universidade da Amazônia - UNAMA eugeniacabral@unama.br

Recebido em 25/março/2014

Aprovado em 12/dezembro/2014

Sistema de Avaliação: Double Blind Review

Esta obra está sob uma Licença Creative Commons Atribuição-Uso. 


\title{
RESUMO
}

A mobilização política em defesa do meio ambiente, nas últimas décadas, em nível internacional, promoveu discussões sobre sustentabilidade, o que resultou em mudanças nos modelos de gestão organizacional, em resposta a pressões exercidas por organismos internacionais e por ambientalistas. Tais pressões condicionam mudanças de comportamento organizacional e medidas regulamentadoras que propiciem maior controle de suas ações. $\mathrm{O}$ estudo objetiva analisar formas de atuação das Instituições de Ensino Superior (IES) na construção de um novo modelo de gestão, que incorpore a dimensão socioambiental e contribua para a sustentabilidade. Para tal, são analisadas algumas experiências em instituições brasileiras e de outros países quanto à adoção da sustentabilidade como modelo de gestão ou princípio norteador desta. Trata-se de uma pesquisa bibliográfica e documental, parte de um estudo mais amplo, ainda em construção, que busca evidências de sustentabilidade, particularmente em uma instituição de ensino superior na Amazônia brasileira - a Universidade Federal Rural da Amazônia (UFRA). Os resultados do estudo mostram que IES estão na vanguarda da construção de conhecimento e de valores sustentáveis, bem como na incorporação desses conhecimentos e valores nos seus modelos de gestão. São evidências de possíveis caminhos que uma IES pode seguir para tornar-se uma Organização Sustentável.

Palavras-chave: Sustentabilidade. Ensino Superior. Organização Sustentável.

\begin{abstract}
The political mobilization in defense of the environment, in recent decades, internationally promoted discussions about sustainability, which resulted in changes in the models of organizational management in response to pressure from international organizations and environmentalists. These pressures affect changes in organizational behavior and regulatory measures that provide greater control of their actions. The study aims to analyze forms of performance of Higher Education Institutions (HEIs) in building a new management model that incorporates environmental dimension and contribute to sustainability. It analyzes some experiences in Brazilian institutions and other countries on the adoption of sustainability as a management style or guiding principle of this. It is a bibliographic and documentary research, part of a larger study that seeks evidence of sustainability, particularly in a Brazilian University - the Federal Rural University of Amazonia (UFRA). The results of the study show that HEIs are at the forefront of knowledge building and sustainable values as well as the incorporation of such knowledge and values into their business models. It's evidence of possible paths that an HEI can follow to become a Sustainable Organization.
\end{abstract}

Keywords: Sustainability. Higher Education. Sustainable Organizational. 


\section{INTRODUÇÃO}

Frente ao agravamento dos problemas ambientais, que marcou o final do século XX, observa-se a introdução do tema da sustentabilidade às agendas políticas dos gestores públicos e privados. Nesse contexto, as organizações, de um modo geral, se viram pressionadas a contribuírem para a preservação do meio ambiente, preocupando-se com os limites do planeta, o que provocou a adoção de sistemas de gestão ambiental e o desenvolvimento de ações de responsabilidade social e ambiental, que podem se traduzir em mudanças nos modelos de gestão e na cultura organizacional. Assim, foram observadas mudanças nas formas de produção e aplicação de novas tecnologias, nas formas de utilização de materiais, no tratamento de resíduos e gerenciamento de água e energia, entre outras. Tais mudanças indicam a assim chamada Sustentabilidade Organizacional.

A sustentabilidade organizacional representa um modelo de gestão de negócios, advinda do movimento a favor do Desenvolvimento Sustentável, visto que é baseada não somente no aspecto financeiro, mas essencialmente no social e no ambiental, o triple bottom line (NASCIMENTO, 2008).

A partir de meados de 1990, as universidades, especialmente em nível internacional, têm participado ativamente do movimento em prol da sustentabilidade, e embora represente um campo novo de pesquisa, vários estudos têm sido publicados a esse respeito (MADEIRA, 2000; NICOLAIDES, 2006; HASAN; MORRISON, 2011). Considerando o papel essencial da educação no processo de conscientização e mudança cultural dos cidadãos e das organizações, Gadotti (2000) explica que a educação do futuro deve estar baseada em sete categorias: cidadania, sustentabilidade, globalização, virtualidade, transdisciplinaridade, dialogicidade e planetaridade. Entre estas, o autor distingue quatro como as que possuem maior relação com o desenvolvimento sustentável: cidadania, sustentabilidade, transdisciplinaridade e planetaridade.

Este trabalho se desenvolve com a finalidade de somar aos estudos sobre a temática da sustentabilidade na educação superior, procurando identificar o que têm realizado as Instituições de Ensino Superior no Brasil e no mundo sobre a sustentabilidade, ou seja, como essas organizações incorporam a questão socioambiental e a sustentabilidade em seus modelos de gestão, e como essas iniciativas podem ser evidências de mudanças na cultura organizacional. Em geral, o estudo objetiva analisar formas de atuação das Instituições de Ensino Superior na construção de um novo modelo de gestão, que incorpore a dimensão 
socioambiental e contribua para a sustentabilidade. Para tal, analisa algumas experiências em instituições brasileiras e de outros países quanto à adoção da sustentabilidade como modelo de gestão. Trata-se de uma pesquisa bibliográfica e documental, parte de um estudo mais amplo, ainda em construção, que busca evidências de sustentabilidade, particularmente em uma instituição de ensino superior na Amazônia brasileira - a Universidade Federal Rural da Amazônia (UFRA), considerando aspectos da gestão organizacional e projetos de extensão desenvolvidos no âmbito desta instituição.

O estudo das práticas sustentáveis nas IES tem como objetivo geral analisar se a gestão dessas organizações incorporou a sustentabilidade, aqui entendida como um novo valor, uma ética. Em termos específicos busca identificar práticas desenvolvidas no âmbito dessas IES que contribuem para minimizar os impactos ambientais decorrentes de suas ações e das ações de outras organizações; bem como identificar como as IES estudadas tratam a sustentabilidade no contexto de suas práticas.

Este artigo está estruturado em três partes, além da introdução e das considerações finais. Inicialmente são apresentados alguns marcos políticos e institucionais bem como diretrizes para a sustentabilidade em instituições de ensino superior; em seguida é feita uma breve discussão acerca do tema cultura organizacional, sustentabilidade e universidades; por fim, no item 4, são identificadas as experiências de sustentabilidade em instituições de ensino superior, em diversos países, no mundo e no Brasil.

\section{MARCOS POLÍTICOS E INSTITUCIONAIS PARA A SUSTENTABILIDADE EM INSITUIÇÕES DE ENSINO SUPERIOR}

A Conferência das Nações Unidas em Estocolmo, em 1972, abriu as discussões e incrementou o interesse internacional pelo que vem sendo definido como o papel do ensino superior na promoção de um mundo sustentável. A Declaração elaborada no âmbito da Conferência de Estocolmo, em 1972, em seu princípio 19, definiu que a educação ambiental deve ser trabalhada desde a escola primária até a idade adulta, como forma de melhorar o comportamento das pessoas, das organizações e de seus dirigentes com relação à proteção do ambiente. Desde esse momento muitos documentos trataram da importância da educação para a construção de um futuro sustentável.

Em 1977, na Conferência Intergovernamental sobre Educação Ambiental, em Tbilisi, Geórgia, foi redigida a primeira declaração internacional sobre educação ambiental. Em umas das recomendações da Declaração de Tbilisi tem-se o reconhecimento do aspecto 
interdisciplinar da educação ambiental (TBILISI, 1977, p. 33).

Kraemer (2000) aprofunda o tema ao argumentar que as instituições de ensino superior têm papel fundamental no preparo das novas gerações. Através de seus estudos, a autora argumenta que compete a estas organizações, além de alertar para os problemas ambientais, sociais e econômicos, apontar soluções e alternativas. As instituições de ensino, por intermédio de sua gestão e de projetos educativos, devem dar exemplos à sociedade, em geral, adotando tecnologias e revisando seus programas de ensino. Nesse sentido, conforme seus argumentos, os trabalhos desenvolvidos por esses estabelecimentos devem servir de parâmetros para as demais organizações. Esclarece ainda a autora que a prática pedagógica que tem uma leitura de compreensão da vida de uma forma sistêmica, permite ao aluno um aprendizado mais completo, real, modificando sua concepção de relação homem- natureza, de meramente contemplativa e utilitária para uma concepção mais complexa, de interdependência.

Conforme destaca Delors (1999), em conformidade ao que foi definido no Relatório da UNESCO (Talloires Declaration, 1990) para educação do Século XXI, o caráter complexo das universidades está intimamente relacionado aos inúmeros papeis por elas desenvolvidos, tais como: ser o lugar onde se aprende e é fonte de saber; acompanhar a evolução do mercado de trabalho; ser o lugar de cultura e de estudo aberto a todos; ser o lugar onde se produz e se socializa o conhecimento. Portanto, com o objetivo de atender às demandas impostas, as universidades comprometem-se com ações estratégicas que possam dar conta do cumprimento desses inúmeros papéis. Para isso, tais quais nas organizações de outra natureza, nas universidades são necessárias reformulações em seus processos, em seus modelos de gestão, para que estas possam contribuir par a formação da consciência sustentável.

A Agenda 21 (Declaração do Rio) chamou a atenção, várias vezes, para o tema da educação como prioridade da construção de um mundo sustentável. Este documento ressaltou a importância da integração da informação como possibilitadora da incorporação de considerações ambientais em decisões sociais e econômicas. Em seu capítulo 36, que trata de Educação, Formação e Conscientização, a Agenda 21 defende a educação como a base para a proteção do meio ambiente (RIBEIRO, 2006).

Vale ressaltar que a popularização, em nível global, da temática sustentabilidade no ensino superior se deu com a Declaração de Talloires, em outubro de 1990, na Universidade de Tufts (Talloires - França). Essa declaração, que expressa grande preocupação com o 
aumento da poluição e da degradação ambiental, foi assinada por reitores das universidades americanas e de todos os demais continentes, assim como por presidentes de mais de quarenta países, esquematizando um planejamento com 10 itens a serem seguidos para a construção de uma universidade sustentável, destacando, por exemplo: a figura do professor como alfabetizador ambiental; o envolvimento das universidades em pesquisa e desenvolvimento de programas sobre população, desenvolvimento e meio ambiente; criação de políticas de conservação de recursos e redução de resíduos no campus e estabelecimento de parcerias com os níveis primários e secundários (KRAEMER, 2000).

Em dezembro de 1991, no Canadá, em Halifax, a Associação Internacional das Universidades, com a Associação das Universidades e Faculdades do Canadá, em reunião com reitores de Universidades de vários países, discutiram ações a serem implementadas pelas Universidades, visando à construção sustentável, entre as quais destacaram: a obrigação ética, a utilização dos recursos intelectuais e a cooperação com todos os segmentos da sociedade (KRAEMER, 2000).

Na Conferência do Rio, em 1992, o capítulo 36 da Agenda 21, trouxe como título da área programática reorientar a educação para o desenvolvimento sustentável, como se vê:

a educação é vital à promoção do desenvolvimento sustentável e à melhoria das capacidades humanas em lidar com as questões do ambiente e do desenvolvimento; a educação é também vital ao alcance de uma ética e consciência ambiental, de valores e atitudes, habilidades e comportamentos consistentes com o desenvolvimento sustentável e para uma efetiva participação pública nos processos decisórios.

Em novembro de 1993, em Kyoto, no Japão, a Associação Internacional das Universidades (IAU) e seus líderes universitários reuniram-se, novamente, para estabelecer diretrizes a serem seguidas, com base nos dispositivos aprovados nas conferências de Talloires (1990), Halifax (1991) e Swansea (1993). As principais medidas definidas foram:

Pressionar as universidades na adoção de práticas sustentáveis de acordo com suas missões; utilizar os recursos das universidades, para esclarecimento dos riscos que ameaçam o planeta e para melhor compreensão por parte do governo e da sociedade das dimensões internacionais do desenvolvimento sustentável; sublinhar a obrigação ética da geração presente, comprometendo-a com a diminuição de práticas abusivas responsáveis pela insustentabilidade ambiental; potenciar a capacidade da universidade no ensino e pesquisa com princípios de desenvolvimento sustentável; cooperar entre si e com todos os segmentos da sociedade, na criação de iniciativas de desenvolvimento sustentável; 
encorajar as universidades a rever as suas próprias ações de forma a refletir as melhores práticas de desenvolvimento sustentável (KRAEMER, 2004, p. 12).

Em 1988, por ocasião da Conferência dos Reitores da Europa, foi lançada a Carta Patente da Universidade para o Desenvolvimento Sustentável, definindo uma série de princípios a serem adotados pelas Universidades com vista ao desenvolvimento sustentável. A denominação Copernicus, está vinculada ao Programa Copernicus, que reúne órgãos de pesquisa e universidades europeias em uma cadeia de cooperação para a pesquisa e desenvolvimento sustentável. Este Programa age com o objetivo de tornar a sustentabilidade uma realidade na pesquisa e no ensino europeu, utilizando princípios de sua carta, como mostra o Quadro 1, a seguir.

\begin{tabular}{|c|c|c|c|}
\hline Objetivos Gerais & Prioridades & Áreas-chave & Ações Copernicus \\
\hline \multirow{3}{*}{$\begin{array}{l}\text { Identificar formas de as } \\
\text { universidades ajudarem } \\
\text { a sociedade a responder } \\
\text { ao desafio do } \\
\text { desenvolvimento } \\
\text { sustentável }\end{array}$} & $\begin{array}{l}\text { Gerar conhecimento em } \\
\text { desenvolvimento } \\
\text { sustentável }\end{array}$ & $\begin{array}{l}\text { Investigação } \\
\text { multidisciplinar; } \\
\text { Redes de peritos }\end{array}$ & $\begin{array}{l}\text { Seminário virtual em } \\
\text { expansão e } \\
\text { desenvolvimento } \\
\text { sustentável }\end{array}$ \\
\hline & $\begin{array}{l}\text { Disseminar conhecimento } \\
\text { em desenvolvimento } \\
\text { sustentável aos alunos }\end{array}$ & $\begin{array}{l}\text { Formação de professores } \\
\text { Currículos universitários } \\
\text { em desenvolvimento } \\
\text { sustentável }\end{array}$ & 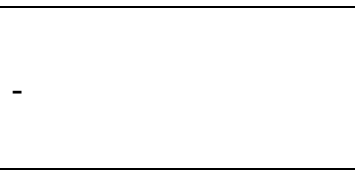 \\
\hline & $\begin{array}{l}\text { Disseminar conhecimento } \\
\text { em desenvolvimento } \\
\text { sustentável à sociedade }\end{array}$ & $\begin{array}{l}\text { Parcerias e redes de } \\
\text { trabalho a nível local; } \\
\text { Serviço à sociedade em: } \\
\text {-ciência e investigação; } \\
\text {-definição de políticas; } \\
\text { desenvolvimento de } \\
\text { capacidades; } \\
\text {-transferência } \\
\text { tecnológica. }\end{array}$ & $\begin{array}{l}\text { Conferências anuais, } \\
\text { desde 1998: Sustainable } \\
\text { Universities: inter-, } \\
\text { multi-and trans- } \\
\text { disciplinary issues and } \\
\text { options, (Barcelona, } \\
\text { 1999). }\end{array}$ \\
\hline $\begin{array}{l}\text { Alcançar a } \\
\text { sustentabilidade nas } \\
\text { universidades }\end{array}$ & $\begin{array}{l}\text { Implementar práticas } \\
\text { ambientalmente } \\
\text { responsáveis pelas e nas } \\
\text { universidades }\end{array}$ & $\begin{array}{l}\text { Promover a gestão } \\
\text { ambiental das } \\
\text { universidades } \\
\text { Promover padrões } \\
\text { sustentáveis de produção } \\
\text { e consumo nas } \\
\text { universidades }\end{array}$ & $\begin{array}{l}\text { Projetos: } \\
\text {-Universidade de baixa } \\
\text { energia; } \\
\text {-Campus-solar europeu } \\
\text {-Química sustentável }\end{array}$ \\
\hline
\end{tabular}

Quadro 1 Estratégia do Programa Copernicus para o Desenvolvimento Sustentável.

Fonte: Disponível em:< http://copernicus-campus.org/. Acesso em: 21 de set./2012.

A Organização das Nações Unidas sistematizou e publicou em documentos oficiais, medidas a serem implementadas pelas Universidades, para o Desenvolvimento Sustentável, resultantes das Conferências Internacionais. Os documentos das Conferências em Desenvolvimento Humano, em 1972, e em Ambiente e Desenvolvimento (UNCED, em 1999), traçaram metas a esse respeito às instituições de ensino superior (Quadro 2). 
DOI: http://dx.doi.org/10.5007/1983-4535.2015v8n1p236

\begin{tabular}{|c|c|c|}
\hline Documentos & Objetivos & Medidas Recomendadas \\
\hline $\begin{array}{l}\text { UNCHD (1972) } \\
\text { Declaração de } \\
\text { Estocolmo } \\
\text { (Princípios } 9 \text { e 24) }\end{array}$ & $\begin{array}{l}\text { Prever e/ou minorar aspectos } \\
\text { contrários ao desenvolvimento } \\
\text { sustentável. }\end{array}$ & $\begin{array}{l}\text { Formulação de acordos multi ou bilaterais ou de } \\
\text { outras formas de cooperação (nomeadamente } \\
\text { em transferência tecnológica). }\end{array}$ \\
\hline $\begin{array}{l}\text { UNCED (1991) } \\
\text { Relatório do } \\
\text { Comitê } \\
\text { Preparatório } \\
\end{array}$ & $\begin{array}{l}\text { Envolver todos na educação para o } \\
\text { desenvolvimento sustentável. }\end{array}$ & $\begin{array}{l}\text { Envolvimento de decisores no governo, de } \\
\text { especialistas que os aconselhem nas } \\
\text { universidades, institutos de investigação, etc. }\end{array}$ \\
\hline $\begin{array}{l}\text { UNCED (1992) } \\
\text { Declaração do Rio } \\
\text { (Princípio 9) }\end{array}$ & $\begin{array}{l}\text { Fortalecer o desenvolvimento de } \\
\text { capacidades para o } \\
\text { desenvolvimento sustentável. }\end{array}$ & $\begin{array}{l}\text { Intercâmbio de conhecimento científico e } \\
\text { tecnológico. Desenvolvimento, adaptação, } \\
\text { difusão e transferência de tecnologias, incluindo } \\
\text { as novas e invocativas. }\end{array}$ \\
\hline \multirow{3}{*}{$\begin{array}{l}\text { UNCED (1992) } \\
\text { Agenda } 21 \\
\text { (Capítulos } 31,34, \\
35 \text { e 36) }\end{array}$} & $\begin{array}{l}\text { Clarificar o papel da ciência e } \\
\text { tecnologia no desenvolvimento } \\
\text { sustentável. }\end{array}$ & $\begin{array}{l}\text { (Re)desenho dos programas nacionais em } \\
\text { Ciência e Tecnologia por forma a clarificar } \\
\text { contribuições do setor para o desenvolvimento } \\
\text { sustentável e identificar funções/ } \\
\text { responsabilidades do sector no desenvolvimento } \\
\text { humano. }\end{array}$ \\
\hline & $\begin{array}{l}\text { Gerar e disseminar conhecimento e } \\
\text { informação em desenvolvimento } \\
\text { sustentável. }\end{array}$ & $\begin{array}{l}\text { Produção de avaliações científicas de longo } \\
\text { prazo sobre depleção dos recursos, uso da } \\
\text { energia, impactos na saúde e tendências } \\
\text { demográficas, e tornar públicas em formas } \\
\text { amplamente compreendidas. }\end{array}$ \\
\hline & $\begin{array}{l}\text { Educar todos para o } \\
\text { desenvolvimento sustentável. }\end{array}$ & $\begin{array}{l}\text { Desenvolvimento de programas de educação em } \\
\text { ambiente e desenvolvimento (acessível a } \\
\text { pessoas de todas as idades). Incentivos dos } \\
\text { países às universidades e a redes de trabalho } \\
\text { neste âmbito. }\end{array}$ \\
\hline
\end{tabular}

Quadro 2 A ONU e as Universidades, no âmbito do Desenvolvimento Sustentável (1972-1992).

Fonte: Disponível em: < http://www.campus.unl.pt $>$. Acesso em: 04 abr./2012.

Em janeiro de 2005, a educação para a sustentabilidade ganhou novo ânimo com a Resolução 254, da Assembleia das Nações Unidas, instituindo a Década da Educação para o Desenvolvimento Sustentável, chamando as Instituições de Ensino a cumprirem o seu papel no processo como responsáveis pela formação de novas idéias. Mais recentemente, em 2012, uma nova convocação da ONU à reflexão sobre desenvolvimento sustentável deu origem à Conferência Internacional sobre o Meio Ambiente, conhecida por Rio+20. Nesse contexto, foram firmados compromissos, por parte dos países participantes, para desenvolverem ações de controle e estímulo às práticas sustentáveis em vários níveis e setores. Entre esses compromissos destacam-se (MMA, 2012, p.47):

Encorajar as instituições de ensino a considerarem na adoção de boas práticas em gestão da sustentabilidade em seus campi e em suas comunidades, com a participação ativa dos alunos, professores e parceiros locais, e ensinando o desenvolvimento sustentável como um componente integrado a todas as disciplinas. 
Ressaltar a importância de apoiar instituições de ensino, especialmente instituições de ensino superior, em países em desenvolvimento, para efeito de investigação e inovação para o desenvolvimento sustentável, nomeadamente no domínio da educação, para desenvolver programas de qualidade e inovadores, incluindo o empreendedorismo e formação profissional habilidade profissional, formação técnica, profissional e aprendizagem ao longo da vida, orientada para preencher as lacunas de competências para promover os objetivos nacionais de desenvolvimento sustentável.

Por ocasião dessa Conferência, aproximadamente 300 instituições de ensino superior de, cerca de 50 países, assinaram a "Iniciativa de Sustentabilidade na Educação Superior", documento elaborado através da convocação da Agência da ONU para a Educação, Ciência e Cultura (UNESCO), a Universidade das Nações Unidas, o Pacto Global e o Programa Ambiental das Nações Unidas (UNEO), que assinala a adesão das Universidades à causa do desenvolvimento sustentável, através da inclusão do tema nos componentes curriculares universitários. Das ações propostas neste documento destacam-se "ensinar o conceito de desenvolvimento sustentável; incentivar a investigação sobre questões de desenvolvimento sustentável, para melhorar a compreensão científica; tornar nossos campi mais 'verdes'; apoiar os esforços de sustentabilidade nas comunidades onde estamos instalados" (RIBEIRO, 2006, p.93).

No Brasil, os apelos da Rio +20 , resultaram em compromisso de incluir a sustentabilidade no currículo acadêmico de todas as Instituições de Ensino Superior e, em um futuro, de médio prazo, estender esta medida da pré-escola ao ensino médio, medida publicada em 18 de junho de 2012, no Diário Oficial da União (RESOLUÇÃO CNE/CP N. $02 / 2012)$.

\section{CULTURA ORGANIZACIONAL, SUSTENTABILIDADE E UNIVERSIDADE}

Para efeito deste estudo, que trata da interação entre cultura organizacional e sustentabilidade, por cultura organizacional entende-se "o modelo dos pressupostos básicos, que determinado grupo inventou, descobriu ou desenvolveu no processo de aprendizagem para lidar com os problemas de adaptação externa e integração interna" conforme definição de Schein (1993).

Nessa perspectiva a cultura organizacional resulta de processos de interações desenvolvidas por grupos em uma determinada organização, frente aos problemas cotidianos de integração e de adaptação. Conforme argumenta Freitas (2007), do processo de interação 
nasce uma cultura permeada por comportamentos, ideologias, valores e normas, que são absorvidos e ou rejeitados. Este autor considera que a cultura organizacional orienta os objetivos oriundos da missão da organização, os valores a serem seguidos nos processos de tomada de decisão. Este conjunto de valores, chamado cultura organizacional, será como um guia na adoção das ideias sustentáveis na organização e, caso esta mudança aconteça, viabilizará uma transformação no comportamento organizacional.

No contexto da chamada "crise ambiental" e, concebendo o mundo como um espaço minado de conexões variadas, onde os sistemas interagem entre si e recebem influências externas, continuamente, todos os espaços de convivência são levados a refletirem acerca de suas formas de atuação no ambiente, especialmente aquelas organizações que provocam significativos impactos ambientais em seus processos de produção. Nesse cenário, considerando as especificidades das IES, públicas ou privadas, quanto ao papel social e político, por elas desempenhados na sociedade onde atuam, como responsáveis pela construção de conhecimento científico, torna-se relevante indagar como estas organizações tratam a questão socioambiental em suas atividades, meio e fim.

Chamadas a responderem as expectativas de seus públicos, externo e interno, as organizações, de um modo geral, se veem pressionadas a dar respostas às pressões em defesa do meio ambiente e com isso a contribuírem para o processo de transformação da consciência acerca do uso dos recursos naturais e dos limites do planeta. Nesse sentido, são observadas mudanças nas formas de produção e aplicação de novas tecnologias, nas formas de utilização de materiais, no tratamento de resíduos e gerenciamento de água e energia, entre outras. Tais mudanças indicam a chamada Sustentabilidade Organizacional, que tem influenciado fortemente na cultura da organização (FLEURY, 1996).

Mesmo organizada por padrões não oficializados, a cultura organizacional na esfera pública caracteriza-se por conter peculiaridades favoráveis à análise, em virtude de ser estruturada como um grande conjunto de normas regras de caráter impessoal - como em toda burocracia - o que, até certo ponto, determina o espaço organizacional. Fleury (1996) argumenta que a cultura organizacional burocrática, tão presente na esfera pública, expressa uma cultura do tipo hierarquizada com diretrizes de autoridade bem delineadas, caracterizando organizações em sua maioria maduras e estáveis.

No campo das organizações burocráticas, a universidade representa uma complexidade, que ora lhe coloca similarmente às organizações burocráticas, ora, como um 
caso especial de burocracia. Ao mesmo tempo, que atua como centro de pesquisa, com estrutura direcionada para isso como material, instalações, mão-de-obra especializada e equipamentos, tem também o papel de ser um centro propagador de conhecimento, com atuação nas áreas de ensino e na área social (ETCHEVERRY, 2003). Com uma atuação tão diversificada, trabalhando com categorias tão diversas, permeadas pela questão política, a cultura organizacional da Universidade dificilmente será tão intensa em outro tipo de organização.

Kraemer (2000), explica que existe um dinamismo nas culturas acadêmicas que estão em constante mudança, e sua evolução resulta da dialética resistência e acomodação a conceitos novos, paradigmas diferentes e práticas inovadoras; uma dialética permeada por conflitos, consenso e negociação. O autor comenta que mesmo sofrendo influências externas, tais como políticas governamentais, normatização, práticas empresariais ou ideologismos vindos da sociedade ela também pode e deve ter papel determinante na elaboração de políticas públicas, na ação das organizações e na sociedade de forma geral.

\section{EDUCAÇÃO SUPERIOR E UNIVERSIDADE SUSTENTÁVEL}

Uma educação voltada para o Desenvolvimento Sustentável deve expressar algumas características como: ter como objetivo a aquisição de valores, ser holística e interdisciplinar, desenvolver o pensamento crítico, incentivar a participação nos processos de tomada de decisão e estar alinhada com as peculiaridades da vida local. Ao serem trabalhados, esses valores devem apontar fundamentalmente para o respeito à pessoa e suas necessidades e respeito ao ambiente (DÉCADA DA EDUCAÇÃO, 2005).

Estudiosos do tema argumentam que as IES devem contribuir para o desenvolvimento sustentável, em suas práticas, no campo do ensino, da pesquisa e da extensão, pela responsabilidade intelectual que possuem, sendo que para isso algumas competências são requisitos para facilitar o entendimento dos problemas enfrentados pelas sociedades e a importância de uma concepção sustentável de sociedade (MADEIRA, 2008). Para Madeira, uma universidade sustentável pode ser caracterizada como aquela que objetiva muito mais que um ensino de qualidade; que deve promover reflexão para incorporação de valores humanos; implementar práticas que promovam melhor qualidade de vida às pessoas que nela convivem; deve preocupar-se com a utilização e gerenciamento de recursos naturais, executar práticas interdisciplinares de aprendizagem através do ensino, da pesquisa e da extensão. 
Chauí (2003) por sua vez, afirma que uma universidade sustentável auxilia os estudantes na compreensão da degradação do ambiente, estimula-os a práticas ambientalmente sustentáveis e os sensibiliza para as injustiças. Para Hall (1982), a comunidade de uma universidade sustentável deve agir em seu cotidiano de maneira a defender o ambiente da organização e contribuir para melhorar a saúde e o bem-estar da população, em geral e dos ecossistemas.

Os autores aqui referidos argumentam que uma instituição que caminha para a sustentabilidade deve comprometer-se com a sustentabilidade em seus documentos oficiais e em seus objetivos estratégicos; aderir aos conceitos de sustentabilidade no ensino de suas disciplinas e na pesquisa; incentivar seus estudantes a reflexão crítica sobre problemas ambientais; planejar práticas e políticas que reduzam a pegada ecológica da organização; incrementar serviços de apoio aos alunos que realcem a sustentabilidade; fomentar acordos de cooperação, em nível local e global, para melhorar a sustentabilidade.

De acordo com as atas da Conferência Campus Earth Summit, universidade sustentável aquela onde:

a sustentabilidade ambiental é prioridade; o conhecimento ambiental faz parte disciplinas mais relevantes; existem oportunidades para que os alunos conheçam os problemas ambientais do campus e também locais; as condições ambientais do campus são monitoradas; há preocupação com compras ambientalmente responsáveis; se busca firmemente a redução de resíduos produzidos no campus; é gerenciado o nível de eficiência energética no campus; é desenvolvido um núcleo ambiental com participação de alunos, professores e técnicos; ocorre um apoio para que os estudantes busquem carreiras ambientalmente responsáveis (HALL, 1982, p.102).

Outra conceituação importante encontra-se no relatório de indicadores de sustentabilidade da Pennsylvania State University (Penn State Green Destiny Council, 2000), o qual caracteriza uma Faculdade ou Universidade sustentável aquela cuja projeção de futuro é manter-se boa, onde entre seus valores estejam incluídos o respeito pela vida em todas as suas formas, a preocupação de viver dentro dos limites saudáveis planetários, transparência na utilização dos recursos financeiros e responsabilidade social e cívica.

Trabalhos com estudos de caso sobre "boas práticas" de sustentabilidade apontam que os estabelecimentos de ensino superior sustentáveis caracterizam-se por relacionar o tema da sustentabilidade transversalmente em suas funções principais de ensino, na pesquisa, nos serviços prestados à sociedade e nas suas operações administrativas, de forma sistêmica (NEJATI; NEJATI, 2012). A esse respeito vejamos no item 4.1, a seguir. 
4.1 EXPERIÊNCIAS DE SUSTENTABILIDADE NA EDUCAÇÃO SUPERIOR, EM NÍVEL MUNDIAL

Em nível mundial, o Japão é considerado como um dos países à frente do movimento da Educação para o Desenvolvimento Sustentável e o ensino superior desponta, também, como exemplo (NOMURA; ABE, 2010). Esses autores destacam a relevância das ações do Ministério da Educação, Cultura, Desporto, Ciência e Tecnologia e do Ministério do Meio Ambiente para a EDS em universidades japonesas. Inúmeras políticas de investimento têm sido desenvolvidas, estimulando lideranças para a sustentabilidade entre os técnicos das universidades, pois, como iniciativa essencial para o aperfeiçoamento da área da sustentabilidade no ensino superior japonês. Nomura e Abe (2010), porém, que mesmo sendo a educação ambiental já desenvolvida no Japão, as pesquisas sobre a EDS são raras e pouco divulgadas.

O Canadá, já possui há algum tempo um destaque no movimento estudantil para a sustentabilidade na Educação Superior. Desde 1996, foi criada uma organização financiada com investimentos privados e públicos de monitoramento do projeto Campus Sustentáveis, que estimula as práticas sustentáveis vinculadas à missão do ensino superior: o Canadian Sierra Youth Coalition. Com este projeto, algumas mudanças significativas foram identificadas, como por exemplo: implantação de sistemas de gestão ambiental em vários campi, programas de uso eficiente de água, energia, transportes e gerenciamento de resíduos (Sustainable Campuses, Dezembro de 2007).

Nos EUA várias experiências merecem destaque, a exemplo da Universidade de Buffalo que tem múltiplas políticas relevantes para a sustentabilidade ambiental. Apesar de esta instituição ter assinado a Declaração de Talloires em 1999, muitas das políticas ambientais já tinham sido desenvolvidas antes desta data. A Universidade de Buffalo desenvolveu cerca de 15 medidas diretamente relacionadas com atividades ambientais no campus, das quais se destacam as relacionadas com a eficiência energética e com o consumo de energia. Um levantamento realizado com estudantes do ensino superior no Havaí e Alabama, com o objetivo de compreender quais as percepções dos estudantes sobre a sustentabilidade no campus identificou, que uma grande parcela (57\% do Alabama e $69 \%$ do Havaí) concorda que é necessário tornar a sustentabilidade prioridade no plano anual do campus e nas atividades diárias (EMANUEL; ADAMS, 2011). A Universidade Estadual de Nova Iorque desenvolve um plano de conservação energética copiado por outras 
universidades americanas, por ter apresentado ótimos resultados na redução do consumo de energia. No entanto, em se tratando de educação ambiental, estudos de Buffalo (EMANUEL; ADAMS, 2011), afirmam não ser este um quesito considerado prioridade para os dirigentes. Um programa intitulado "Iniciativa da Universidade Sustentável" (Sustainable University of Michigan), foi implementado pela Universidade de Michigan em 2006, apresentando índices satisfatórios de aprovação da comunidade acadêmica (EMANUEL; ADAMS, 2011).

A Universidade de Tecnologia de Sidney criou o Instituto para o Futuro Sustentável, cuja finalidade é desenvolver ações de pesquisa, ensino e consultoria em conjunto com o Governo, Indústria e sociedade para um futuro sustentável. Para este estabelecimento, existem grandes obstáculos a serem ultrapassados para se atingir a sustentabilidade ambiental e simultaneamente criar sociedades com padrão de vida aceitável às populações (HALL, 1982).

No que diz respeito aos países europeus, estudos de Hall (1982), exemplificam as iniciativas da Holanda, Alemanha e Reino Unido, como os países que se destacam na implementação de iniciativas sustentáveis nas Universidades. Este autor ressalta que são várias as barreiras que dificultam a multiplicação destas iniciativas para outras universidades: grande parte dos bons exemplos executados não são documentados, de forma eficaz; a maioria dos professores e funcionários percebe a sustentabilidade de uma forma abstrata, e encontram dificuldade em aplicá-la à realidade, por isso, seguem sem fazer nada nesta área. Em síntese, Hall identifica que muitas universidades europeias consideram difícil realizar, concretamente, a sustentabilidade no dia a dia por entendê-la como "complexo", "muito caro" ou "sem importância", justificando algumas vezes mais de um destes itens.

A Holanda tem se mostrado, na ultima década, um país comprometido com a sustentabilidade no ensino superior. Segundo Machado (2010), este êxito é devido a três aspectos: um sistema de cooperação entre as partes relevantes: Governo, Indústria, Universidade e Sociedade; a cultura e o aspecto político que contém em suas diretrizes a sustentabilidade; a adesão do povo à práticas, ao invés de discussões filosóficas. Desde 1995, com a criação da Plataforma Ambiental Holandesa de Alunos, cujas finalidades eram intensificar o fluxo de informações e promover operações sustentáveis no campus e nas grades curriculares, iniciou-se o chamado movimento do Ensino Superior para o DS, que se expandiu anos depois para a atual Rede Holandesa para o Ensino Superior e DS.

$\mathrm{Na}$ Alemanha observa-se um trabalho mais isolado no que se refere ao DS, com pouca troca de experiência e informação. Algumas instituições, entre elas a Universidade Técnica de 
Hamburgo, desenvolvem iniciativas relacionadas à sustentabilidade, assumindo inclusive, o papel de Gabinete Alemão no Programa de Universidades Bálticas, que tem entre suas atribuições, fornecer matéria ambiental aos cursos das Universidades da Europa Central e do Leste (Machado, 2010).

No Reino Unido, 25 Universidades iniciaram em 1997 o projeto chamado: "The Higher Education 21", com o objetivo de promovera exemplos de boas práticas de sustentabilidade no Ensino Superior (Higher Education Partnership for Sustainability, 2003). Através deste projeto, foi desenvolvido, incorporando as variadas dimensões da sustentabilidade, um conjunto de indicadores de sustentabilidade. Também no Reino Unido, em 2001, um projeto com a duração de três anos, estabelecendo a Parceria do Ensino Superior do Reino Unido para a Sustentabilidade, com a finalidade de transformar as instituições participantes e outras que foram atraídas pelos exemplos, bem como criar ferramentas que levassem a uma maior sustentabilidade (RIECHMAN, 2012). Riechman descreve, ainda, a política de DS da Universidade de Hertfordshire, cujos princípios ressaltam a relevância do DS o incentivo aos alunos a conhecerem com maior profundidade o referido tema e a reconhecer os impactos de seus estudos, bem como promover práticas sustentáveis junto á comunidade local.

\subsection{SUSTENTABILIDADE E UNIVERSIDADES BRASILEIRAS}

Depoimentos da Associação Nacional dos Dirigentes das Instituições Federais de Ensino Superior (ANDIFES) mostram que a questão da sustentabilidade precisa ser incorporada às estruturas formais da educação, seja nas universidades, seja nos ciclos básicos. Hoje, o assunto é tratado de maneira periférica. (ANDIFES, 2012). Além disso, Machado et al (2010) considera que se os futuros profissionais não saírem da universidade tendo como ideia cristalizada em suas mentes o papel das diversas áreas de estudo na construção de uma sociedade cada vez mais sustentável, é improvável que darão a ela a importância devida, e que chegarão um dia a aplicá-la de forma consistente no exercício de sua profíssão.

As universidades brasileiras, a exemplo do que já ocorre em outros países, movimentam-se para dar conta deste papel a elas atribuído, seja através do tema da sustentabilidade em seus componentes curriculares, seja em práticas inovadoras na gestão ou no treinamento e desenvolvimento de seus professores e funcionários. Diversos exemplos nacionais têm se mostrado exitosos. (RIBEIRO, 2006). 


\section{PRÁTICAS DE SUSTENTABILIDADE EM INSTITUIÇÕES DE ENSINO SUPERIOR: EVIDÊNCIAS DE MUDANÇAS NA GESTÃO ORGANIZACIONAL \\ DOI: http://dx.doi.org/10.5007/1983-4535.2015v8n1p236}

A Universidade de São Paulo (USP) - a maior universidade pública brasileira, uma das mais bem avaliadas nacional e internacionalmente ( $78^{\circ}$ lugar no ranking mundial em 2012 pela instituição Times Higher Education) - desenvolve diversas ações de sustentabilidade, destacando-se: o projeto desenvolvido pelo Programa USP Recicla (Agência de Inovação) em parceria com a Universidade Autônoma de Madri, que visa cooperação e fortalecer ambas as instituições nas áreas de gestão e educação ambiental, com ações tais como o projeto compostando na creche (USP, 2012).

$\mathrm{Na}$ Universidade de São Carlos merecem destaque as seguintes ações: projeto Recicl@tesc (reciclagem tecnológica de São Carlos); apoio à implantação de coleta seletiva em condomínios, associações, comunidades e escolas de Ribeirão Preto; formação de Educadores Ambientais, em Ribeirão Preto; promoção de cultura da mobilidade sustentável no campus de São Carlos; as atividades de educação e ética ambiental que visa evitar o desperdício; a pegada ecológica no Campus USP de São Carlos; a Moradia Estudantil Sustentável no Campus de São Carlos; o projeto Promovendo Eventos mais Sustentáveis: aa teoria à prática.

A Universidade Federal Espírito Santo criou o Núcleo Interdisciplinar de Pesquisa e Estudo em Educação (NIPEEA), com o objetivo de integrar os projetos de pesquisa em Educação Ambiental. Estabeleceu a formação de uma equipe de docentes e alunos de graduação, mestrado e doutorado em Educação, para discussão de pesquisas já realizadas, elaboração de projetos de Educação Ambiental.

A Universidade Federal de Minas Gerais (UFMG) trabalha com um Programa de Administração e Gerenciamento de Resíduos Sólidos (GERESOL), uma aposta da Universidade frente aos problemas enfrentados na questão dos resíduos sólidos. O GERESOL visa estabelecer diretrizes para o gerenciamento de resíduos sólidos produzidos na UFMG e que fazem parte da política ambiental da instituição (UFMG, 2012).

A Universidade Federal de Lavras (UFLA), pauta suas atividades em relação à sustentabilidade por seu Plano Ambiental e de Infraestrutura elaborado para os próximos 30 anos. Entre as muitas iniciativas contempladas neste Plano destacam-se: projetos de proteção das nascentes e matas ciliares; gerenciamento de resíduos; Incubadora Tecnológica de Cooperativas Populares, para recolocação de profissionais no mercado de trabalho, estação de tratamento de esgotos. A Universidade possui também ciclovias para facilitar a movimentação mais saudável das pessoas dentro do campus. Apontada como a $70^{\mathrm{a}}$ no ranking mundial e a 
primeira universidade brasileira no Green Metric 2012, a UFLA investe esforços nas ações sustentáveis.

Outro exemplo brasileiro de universidade que vem trabalhando em prol da sustentabilidade é a Universidade do Vale do Rio dos Sinos (UNISINOS). Esta Instituição foi a primeira Universidade da América Latina a conseguir a certificação da ISO 14001, através da implantação do projeto verde campus, que objetiva a melhoria, preservação e recuperação da qualidade ambiental, com foco no desenvolvimento socioeconômico, segurança do trabalho, proteção da vida e qualidade ambiental. Este projeto resultou na implementação de um Sistema de Gestão Ambiental que envolve a criação de laboratórios para estudos ambientais, ferramentas de geoprocessamento e pesquisas básicas e aplicadas (VERDE CAMPUS, 1997).

O representante da PUC do Rio de Janeiro, estimulado pelas ideias apreendidas no Colóquio Global de Reitores de Universidades, em $2007^{1}$, abraçou a tarefa de transformar a PUC-RIO em uma Universidade Sustentável, ambientalmente falando. Foi assim que surgiu a Agenda Ambiental dessa instituição, resultado das reflexões promovidas pelos diversos setores da PUC, coordenada pelo Núcleo Interdisciplinar de Meio Ambiente (NIMA). Essa Agenda expressa "um conjunto de práticas que permitam e estimulem a sustentabilidade e a qualidade de vida socioambiental no Campus universitário, tendo como base os princípios humanitários, científicos e éticos". Para tornar realidade os valores definidos na Agenda, em 2008, foi criada a Comissão para a Sustentabilidade do Campus, formada por professores, alunos, funcionários e voluntários e colaboradores. Para que esta agenda não se tornasse apenas mais um documento, foram criados grupos temáticos, de trabalhos específicos: biodiversidade, água e energia, materiais e resíduos e educação ambiental. As propostas contidas na Agenda são divididas em curto, médio e longo prazo e monitoradas pelos grupos respectivos.

Variadas medidas têm sido implementadas, também, pela Universidade Federal de Juiz de Fora (UFJF), como por exemplo: campanha "Recicla-me ou te devoro" de incentivo a práticas e ações sustentáveis; a distribuição de ecobags em eventos na Universidade objetivando despertar nos alunos e funcionários o cuidado com o meio ambiente (UFJF, 2011); a Incubadora Tecnológica de Cooperativas Populares (Intecoop/UFJF) que apoia grupos que reaproveitam o lixo na produção de artesanato. 


\section{PRÁTICAS DE SUSTENTABILIDADE EM INSTITUIÇÕES DE ENSINO SUPERIOR: EVIDÊNCIAS DE MUDANÇAS NA GESTÃO ORGANIZACIONAL \\ DOI: http://dx.doi.org/10.5007/1983-4535.2015v8n1p236}

$\mathrm{Na}$ Universidade Federal de Santa Catarina (UFSC), a criação de uma coordenadoria de Gestão Ambiental, está responsável pela política de gestão ambiental da Universidade e preocupa-se em utilizar o ensino para melhorar a relação homem e meio ambiente, aproveitando a parceria da comunidade para geração, disseminação do conhecimento e melhor qualidade de vida (RIBEIRO et al. 2005). Entre as ações já em andamento destacamse: a coleta dos resíduos químicos da realizada por uma empresa terceirizada que SE responsabiliza pela coleta e destinação final adequada destes resíduos; o Projeto Sala Verde, que se constitui em um espaço próprio ao delineamento e desenvolvimento de atividades educativas de difusão de publicações sobre Meio Ambiente (RIBEIRO et al, 2005).

Outras experiências de gestão ambiental em IES brasileiras ou de incorporação da temática sustentabilidade nas agendas dessas organizações foram identificadas em diversos estudos, a exemplo de: pesquisa realizada na Universidade Estadual de Maringá, por Lima Jr, Oiko e Cavicchioli (2010), que trata da destinação final de resíduos sólidos e avaliação da conscientização ambiental dos funcionários dessa IES; estudo realizado por Gerbase, Coelho e Machado (2005) acerca de práticas de gerenciamentos de resíduos químicos em instituições de ensino e pesquisa; estudo realizado por Imbroisi (2006) entre outros pesquisadores do Instituto de Química da Universidade de Brasília acerca da gestão de resíduos químicos nessa IES. Merece destaque, ainda, pelas contribuições metodológicas e pelos resultados encontrados quanto às lacunas na gestão ambiental dessas organizações, o estudo desenvolvido por Kruger, Freitas, Pfitscher e Petri (2011), que trata do nível de aderência de uma IES Comunitária, localizada no estado de Santa Catarina, aos objetivos da Agenda Ambiental na Administração Pública (A3P).

Tal qual foram identificados pelos estudos aqui referidos, que tratam das evidências da incorporação do princípio da sustentabilidade na gestão de IES brasileiras, estudos mostram que diversas IES localizadas no estado do Pará, também iniciaram, nas últimas décadas, um movimento rumo à sustentabilidade, com a incorporação da temática em programas de extensão, de pesquisa, nos conteúdos curriculares e, embora de forma residual, no âmbito da gestão. Na Universidade do Estado do Pará (UEPA), vê-se a inclusão da temática em seus programas de graduação e pós-graduação. Nesta IES existem, no contexto atual, cursos de graduação, especialização e mestrado na área das ciências ambientais, que vêm promovendo também o aumento da produção científica sobre o assunto. Eventos de divulgação nos campi da Universidade, também vêm sendo realizados com frequência, estimulando a reflexão da 
comunidade acadêmica. Além disso, a UEPA vem participando ativamente de acordos de cooperação com órgãos afins em projetos voltados para a sustentabilidade.

$\mathrm{Na}$ Universidade Federal do Pará (UFPA), a temática da sustentabilidade integra o conteúdo de diversos programas de graduação e pós-graduação (cursos de especialização, mestrado e doutorado). Além disso, esta IES participa de redes de cooperação no Estado, no Brasil e internacionalmente, desenvolvendo projetos de pesquisa com foco no Desenvolvimento Sustentável. Em 2012, a UFPA, lançou o prêmio "Prof. Camilo Vianna: uma cidade sustentável", visando a coleta de ideias para boas práticas sustentáveis no campus. Conforme indicam documentos internos desta IES, constituem exemplos de compromisso da gestão com a sustentabilidade institucional: diminuição do desperdício de recursos naturais, conservação de áreas verdes, coleta seletiva do lixo. Temáticas como biodiversidade, qualidade de vida, inclusão social e desenvolvimento sustentável pautam diversos projetos e ações em desenvolvimento na UFPA (UFPA/PDI, 2011-2015).

No âmbito da Universidade da Amazônia (UNAMA), a maior universidade privada no estado do Pará, a questão da sustentabilidade tem sido incorporada nos conteúdos programáticos dos cursos de graduação, em projetos de pesquisa e de extensão desenvolvidos por professores pesquisadores dessa IES, como destaque para o "Programa Integrado Município Sustentável”, desenvolvido a partir de 2010, que integra ações de ensino, pesquisa e extensão em municípios paraenses. O programa objetiva contribuir para a implantação de um novo modelo de desenvolvimento nos municípios que formam a região na qual a UNAMA está inserida. Busca-se conciliar os objetivos básicos de ensino, pesquisa e extensão da Universidade com os anseios e demandas das diversas coletividades que compõem os territórios municipais da região amazônica, a exemplo dos municípios de Benevides e Abaetetuba participantes desse programa (VASCONCELLOS; VASCONCELLOS; TAVARES, 2012).

Estudo recente realizado no âmbito da Universidade Federal Rural da Amazônia (UFRA), ainda em processo de conclusão, traz evidências da incorporação da sustentabilidade na gestão dessa IES, tanto nas ações desenvolvidas no campo do ensino, da pesquisa, da extensão, bem como da gestão, especialmente quanto à adequação das construções e reformas dos prédios e instalações no Campus Belém. De acordo com os dados e as informações levantadas no setor responsável pelas obras realizadas no Campus Belém, inclusive as que estão em fase de licitação e andamento, as construções obedecem as normas regulamentadoras 
de sustentabilidade, planejadas para que sejam preservadas as áreas verdes, utilizando luminárias reflexivas e lâmpadas econômicas. Além disso, as dimensões das portas e janelas estão adequadas para permitir, além de melhor ventilação, iluminação natural. Os sanitários contam com descarga de vazamento rápido e as instalações hidráulicas estão equipadas com válvulas de retenção, o que vem provocando uma redução no consumo de água e economia de gastos (VIEGAS, 2013).

Dessa forma, percebe-se, uma atenção dos gestores dessas organizações em relação à necessidade de incorporação da sustentabilidade, como princípio da gestão, ainda que esta preocupação esteja revestida, em grande medida, de cumprimento das normas legais.

\section{CONSIDERAÇÕES FINAIS}

Este trabalho procurou contribuir com os estudos sobre a temática da sustentabilidade nas organizações, procurando identificar o que têm realizado as IES no Brasil e no mundo sobre a sustentabilidade, ou seja, como essas organizações incorporam a questão socioambiental e a sustentabilidade em seus modelos de gestão, e como essas iniciativas podem ser evidências de mudanças na cultura organizacional.

As modificações operadas nos processos de trabalho nas IES, referidas neste estudo, demonstram que além da incorporação tema sustentabilidade nos conteúdos curriculares, nos projetos de pesquisa e de extensão, ainda que de forma pontual, há evidências de mudanças nas formas de aplicação de novas tecnologias, nas formas de utilização de materiais, no tratamento de resíduos e gerenciamento de água e energia, entre outras. Tais mudanças indicam a assim chamada Sustentabilidade Organizacional.

Conforme argumentam estudiosos do tema é grande o desafio para tornar uma organização inovadora e sustentável. Representa, entre outras coisas, um quebra-cabeças a ser montado pelos gestores, uma vez que exige reflexão sobre os valores nos quais se baseiam os comportamentos e atitudes dos membros de uma organização, que estão relacionados com a história da organização, com modelos de gestão que não permitem uma visão holística da organização, bem como as condições objetivas para promoveras mudanças necessárias. A complexidade desse processo aumenta à medida que se estende a compreensão do desenvolvimento sustentável às suas variadas perspectivas: ambiental, social, econômica, cultural entre outras (NASCIMENTO, 2008).

No que se refere às Universidades, existe uma expectativa por parte de seus usuários 
de que, sendo centros de ensino, pesquisa e extensão, com um capital intelectual diferenciado, essas organizações possam estar na vanguarda do movimento de transformação das ideias, dos valores e dos modelos de gestão e de desenvolvimento adotados nas organizações e na sociedade em geral, para apoiar o ideal de futuro que se pretende conquistar.

Em resumo, no âmbito das IES brasileiras estudos mostram que há evidências da incorporação da sustentabilidade no campo no ensino, da pesquisa e da extensão, bem como nas práticas de gestão, mais rotineiras, como as descritas neste estudo, como é o caso da coleta seletiva de lixo, do gerenciamento dos resíduos de produtos químicos utilizados nos laboratórios de pesquisa, da adequação das construções às normas e ao princípio da sustentabilidade, à arborização/paisagismo. No entanto, os estudos mostram que a gestão das IES ainda carece de aperfeiçoamento ou inovação, além de conscientização por parte dos gestores e técnicos quanto a compras sustentáveis, por exemplo.

\footnotetext{
${ }^{1}$ Nesse Colóquio se discutiu a missão das universidades no contexto da salvação do planeta, com a participação de diversas universidades do mundo, entre essas a de Harvard, Oxford e o Indian Institute of Technology, de Tokyo, de Kyoto (www.puc-rio.br - acesso em 22/03/2012).
}

\section{REFERÊNCIAS}

ASSOCIATION OF UNIVERSITY LEADER FOR A SUSTAINABLE FUTURE. The Talloires Declaration - 10 point action plan. Taillores: Association of University Leader for a Sustainable Future, 1990.

CABRAL, Eugenia Rosa. Articulação de interesses do empresariado industrial no processo de produção da regulação ambiental: convergências e divergências. Belo Horizonte, 2007. (Tese de Doutorado). Universidade Federal de Minas Gerais.

CHAUI, M. A universidade pública sob nova perspectiva. Revista Brasileira de Educação, n. 24, p. 5-15, nov./dez. 2003.

CLUGSTON, R.M.; CALDER, W. Critical dimensions of sustainability in higher education, In: W. L. Filho (ed.). Sustainability and university life. Peter Lang, New York, 1999.

CMMAD - Comissão Mundial sobre meio-ambiente e desenvolvimento. Nosso Futuro Comum. Rio de Janeiro: Editora da Fundação Getúlio Vargas, 1987.

DELORS, Jacques et al. Educação: um tesouro a descobrir. 3. ed. São Paulo: Cortez; Brasília, DF: MEC: UNESCO, 1999.

DONAIRE, D. A internalização da gestão ambiental na empresa. Revista de Administração, São Paulo, v.31. jan/mar.1996. 
EMANUEL, R.; ADAMS, J.N. College students' perceptions of campus sustainability. International Journal of Sustainability in Higher Education,v. 12, n. 1, p. 79- 92, 2011.

ETCHEVERRY, G.J. La universidad esta siendo despedazada por el mercado: balance de gestión. Clarin, Buenos Aires, abr.2003.

FREITAS, Maria Ester de. Cultura organizacional: evolução e crítica. São Paulo: Thomson Learning, 2007.

FLEURY, M. T. L., O desvendar da cultura de uma organização: uma discussão metodológica. In: FLEURY, M. T. L., FISHER, R. M., Cultura e poder nas organizações. São Paulo: Atlas, 1996.

Fundação Getúlio Vargas (FGV SP). FIS - Formação integrada para sustentabilidade. Disponível em: $<$ http// www.fgv.br/ces/fis. Acesso em: 19 set. 2012.

GADOTTI, M. Perspectivas atuais da educação. Porto Alegre: Artes Médicas Sul, 2000.

GERBASE, Annelise E.; COELHO, Fernando S.; MACHADO, Patrícia F. L.

Gerenciamentos de resíduos químicos em instituições de ensino e pesquisa. Quím. Nova [online]. 2005, vol.28, n.1, pp. 3-3.

HALL, R. H., Organizações. Rio de Janeiro: Prentice-Hall do Brasil, 1982.

HASAN, M.; MORRISON, A. Current University Environmental Management Practices. Journal of Modern Accounting \& Auditing, v. 7, n. 11, p. 1292-1300, 2011.

IMBROISI, Denise et al. Gestão de resíduos químicos em universidades: Universidade de Brasília em foco. Quím. Nova [online]. 2006, vol.29, n.2, pp. 404-409.

KRAEMER, M. E. Responsabilidade social: uma alavanca para a sustentabilidade. Revista Pensar Contábil - Responsabilidade Social e Ambiental. Conselho Regional de Contabilidade do Rio de Janeiro. Rio de Janeiro: Ano III, n. 9, 2000.

A universidade do século XXI rumo ao desenvolvimento sustentável. Revista Eletrônica de Ciência Administrativa - RECADM, v. 3, n. 2, nov./2004. Disponível em: http://revistas.facecla.com.br/index.php/recadm/. Acesso em: fev. 2013.

KRUGER, Silvana Dalmutt; FREITAS, Claudio Luiz de; PFITSCHER, Elisete Dahmer; PETRI, Sergio Murilo. Gestão ambiental em instituição de ensino superior: uma análise da aderência de uma instituição de ensino superior comunitária aos objetivos da agenda ambiental na administração pública (A3P). Rev. GUAL, Florianópolis, v. 4, n. 3, p.44-62, set/dez. 2011.

MACHADO, F. M. C. et al. Sustentabilidade: o que as engenharias têm a ver com isso? In: Congresso Brasileiro de Educação em Engenharia, 38, 2010, Fortaleza. Anais... Fortaleza: ABENGE, 2010.

MADEIRA, A.C.F.D. Indicadores de Sustentabilidade para Instituições de Ensino Superior. 2008, 201p. Dissertação (Mestrado em Engenharia do Ambiente) - Universidade do 
Porto. Porto, 2008.

Ministério do Meio Ambiente - MMA. Declaração final da conferência das Nações Unidas sobre desenvolvimento sustentável (RIO + 20): o futuro que queremos. Brasília, MMA, 2012. Disponível em: http://www.mma.gov.br/port/conama/processos/61AA3835/O-Futuro-quequeremos1.pdf. Acesso em: mar. 2013.

NASCIMENTO, Luis Felipe; LEMOS, Angela Denise da Cunha; MELLO, Maria Celina Abreu de. Gestão socioambiental estratégica. Porto Alegre: Bookman, 2008.

NEJATI, M.; NEJATI, M. Assessment of sustainable university factors from the perspective of university students. Journal of Cleaner Production, Sept.2012. Disponível em:

$<$ http://www.sciencedirect.com/science/article/pii/S095965261 2004714>. Acesso em: 22 mar. 2013.

NICOLAIDES, A. The implementation of environmental management towards sustainable universities and education for sustainable development as an ethical imperative. International Journal of Sustainability in Higher Education, v. 7, n. 4, p. 414-424, 2006.

NIPEEA. NIPPEA. Disponível em:

http://www.seer.furg.br/ojs/index.php/ambeduc/article/viewFile/1603/734. Acesso em: 03 jan. 2013.

NOMURA, K.; ABE, O. Higher education for sustainable development in Japan: policy and progress. International Journal of Sustainability in Higher Education, v.11, n. 2, p. 120$129,2010$.

RIBEIRO, Antonio de Lima. Teorias da administração. 5.ed. São Paulo: Saraiva, 2006.

RIECKMANN, M. Future-oriented higher education: which key competencies should be fostered through university teaching and learning? Futures, v. 44, p.127-135, 2012.

SCHEIN, E.H. Guia de sobrevivência da cultura corporativa. Rio de Janeiro: Ed. José Olimpio, 1999.

SCHUMACHER COLLEGE. Disponível em $<$ http://www.schumachercollege.org.uk $>$. Acesso em: 12 de out. de 2012.

USP - Universidade de São Paulo. TEIA. Laboratório de Educação e Ambiente. Disponível em: http://www.teia.fe.usp.br/?page id=15. Acesso em: 12 de out. 2012.

TBILISI. Intergovernmental Conference on Environmental Education. Organized by Unesco in co-operation with UNEP. Tbilisi (USSR) 14 - 26 OUT. 1977. Disponível em: $<$ http://unesdoc.unesco.org/images/0003/000327/032763eo.pdf $>$. Acesso em: 20 fev. 2013.

ULSF. Talloires Declaration, 1990. Disponível em:

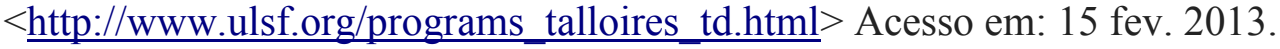

UNESCO. Quatro pilares da educação. Disponível em: http://4pilares.net/text-cont/delorspilares.htm. Acesso: em set. 2012. 
Década da educação das Nações Unidas para o desenvolvimento sustentável $\overline{2005}$-2014: documento final do esquema internacional de implementação. Brasília: UNESCO, 2005.120p. Disponível em: http://unesdoc.unesco.org/images/0013/001399/139937 por.pdf. Acesso em: nov. 2012.

UFPA - Universidade Federal do Pará. Plano de Desenvolvimento Institucional 2011-2015. Disponível em: http://www.portal.ufpa.br/docs/pdi_aprovado_final.pdf. Acesso em: mar.2013.

VASCONCELLOS SOBRINHO, M. ; VASCONCELLOS, A. M. A. ; TAVARES, R. M. Universidade enquanto ator do desenvolvimento local: experiência do Programa Integrado Município Sustentável implantado pela Universidade da Amazônia (UNAMA). ABMES Cadernos, v. 1, p. 47-92, 2012.

VIEGAS, Socorro de F. S. da S. Sustentabilidade em instituições de ensino superior: um estudo na Universidade Federal Rural da Amazônia. Dissertação de Mestrado, Belém, 2013, $\mathrm{PPAD} /$ Unama. 